\title{
Attendance of male partners to different reproductive health services in Shinyanga District, North western Tanzania
}

\author{
ALFRED CHIBWAE ${ }^{1}$, ANTHONY KAPESA ${ }^{2 *}$, OLA JAHANPOUR ${ }^{2}$, JEREMIAH SENI ${ }^{1}$, BASINDA NAMANYA ${ }^{2}$, \\ EMMANUEL KADELYA ${ }^{3}$, EVELYNE KONJE2 ${ }^{2}$, ELIAS C. NYANZA2 ${ }^{2}$ SOSPATRO NGALLABA ${ }^{2}$ and DEBORAH \\ DEWEY4 \\ ${ }^{1}$ Catholic University of Health and Allied Sciences, School of Medicine, P.O. Box 1464, Mwanza Tanzania \\ ${ }^{2}$ Catholic University of Health and Allied Sciences, School of Public Health, P.O. Box 1464, Mwanza Tanzania \\ 3Shinyanga Regional Hospital, P.O. Box 17, Shinyanga, Tanzania \\ ${ }^{4}$ University of Calgary, Department of Paediatrics and Community Health Sciences, Owerko Centre at the Alberta \\ Children's Hospital Research Institute, Canada
}

\begin{abstract}
Background: Male involvement in reproductive health $(\mathrm{RH})$ services in Africa has been associated with improved maternal and child health outcomes. The objective of this study was to determine the prevalence and factors affecting male partner attendance to available reproductive health services in Shinyanga district, north-western Tanzania.

Methods: A house to house survey using a structured questionnaire was conducted among randomly selected married men. Additional in-depth interviews were conducted among married men found attending RH services. Factors that motivates the uptake of locally available RH services together with their partners were explored.

Results: A total of 204 men participated in the study, 94.4\% (193/204) of them reported to have ever attended the RH service with their female partners at least once whereas $50.6 \%(103 / 204)$ of them attended at least thrice. Three quarters (154/204) attended HIV counselling and testing (VCT) and 63\% (129/204) attended antenatal services (ANC). Reported attendance to sexually transmitted infections (STIs/STDs), prevention of HIV transmission from mother to child (PMTCT), and reproductive health cancer services were all less than $13 \%$. The male partners age group $\left(25-34\right.$ years; $\chi^{2}=9 \cdot 347, d f=3 p$-value $<$ 0.001), female partner invitation to HR services $\left(\chi^{2}=29.901, \mathrm{df}=1, \mathrm{p}\right.$-value $\left.<0.001\right)$ and having less than 2 children $\left(\chi^{2}=6.201, d f=2, p\right.$-value $\left.<0.05\right)$ were associated with higher RH service attendance. Only $20 \%$ (4/20) of married men attended RH because they expected better health outcomes in their presence whilst majority attended because they were summoned or just happen to be at the clinic for other purposes.

Conclusion: The male attendance to RH services together with their female partners' in rural Shinyanga was mainly focused ANC and VCT. Most of men attended because were verbally invited by their partners. Education on couple communication empowerment among women attending RH clinics could sustainably improve attendance to all RH services.
\end{abstract}

Keywords: male, attendance, reproductive health, services, motivations, Tanzania

\section{Introduction}

In recent years in Africa increasing efforts have been made to involve men in reproductive health $\mathrm{RH})$ programmes including family planning, eliminating HIV transmission from the mother to the child, and safe motherhood (Kak et al., 2011; Cleland et al., 2011; Afnan-Holmes et al., 2015). The primary aim of these programmes was to reduce maternal and child mortality (WHO, 2002; Sternberg \& Hubley, 2004). Studies have shown that male involvement in RH services is associated with an improved maternal and child health outcomes (Allen et al., 1992 Aluisio et al., 2011; Byamugisha et al., 2011; Yargawa \& Leonardi-Bee, 2015). However, the proportion of male participation in these programmes in Sub- Saharan Africa remains low (Msuya et al., 2008; Peltzer et al., 2011; Haile \& Brhan, 2014). Male partners in African communities are typically the decision makers in all matters pertaining to families (UNICEF, 2005; Angel-Urdinola \& Wodon, 2010; Ganle

\footnotetext{
*Correspondence E-mail: anthony1kapesa@gmail.com
} 
et al., 2015). To ensure improved maternal and child outcomes, the active participation of male partners in RH services along with their female partner remains pivotal.

In Tanzania, male involvement in RH has been a public health concern for many years. Merely $12 \%$ of men in northern Tanzania in 2008 attended HIV voluntary counselling and testing services (VCT); and that that only $40 \%$ of men visited health facilities after their partner had delivered (Msuya et al., 2008). Family planning is still perceived as the responsibility of women despite improving household couple's discussions on the same (Chuwa, 2012; Anasel \& Mlinga, 2014). Western and Lake Victoria Zone regions of Tanzania have been identified as areas with unacceptably high neonatal and maternal mortalities (Michael, 2012). Family planning is now considered the most important intervention to reduce maternal and child mortality and yet Shinyanga has the lowest uptake of contraceptive use in the country (TDHS-MIS, 2016). Without improving rates of male partner engagement, improvement in maternal and child outcomes would be limited (Singh et al., 2003; MoHSW, 2014).

Various individual, health system and social factors have been associated with men's involvement in RH services elsewhere (Ditekemena et al., 2012). The individual factors include fear of HIV status disclosure and perceived side effects of the services or treatments for example of women over bleeding and loss of fertility when using modern contraceptives (Medley et al., 2004; Bajunirwe \& Muzoora, 2005; Kabagenyi et al., 2014). Health system factors affecting men's involvement include lack of good and comprehensive RH services in health facilities, negativity of health workers and lack of space for men in RH clinics and long waiting time (Byamugisha et al., 2010; Ditekemena et al., 2011). Local beliefs such as trust in traditional healers and attitude that RH clinics meant for women affects male involvement in RH programmes (Reece et al., 2010; Ditekemena et al., 2012).

Behavioural maintenance like that of male attendance in RH depends upon internalized values and capacity for change as well as self-determination (Ryan \& Deci, 2000b). Extrinsic and intrinsic motivation work synergistically; the former enhances behaviour or performance by providing individuals with the opportunity to earn rewards or avoid punishment, while the latter is internally driven and leads to a sustained performance (Ryan \& Deci, 2000a). Activities promoting male involvement in $\mathrm{RH}$ in health facilities and in communities in Tanzania have been intensified. However, there is limited evidence on what factors motivate men to attend $\mathrm{RH}$ services especially in north-western part of the country, where indicators on maternal and child health are poor (Msuya et al., 2008; Afnan-Holmes et al., 2015). The primary objective of this study was to investigate the proportion of married men who ever attended the available RH services along with their partners in Shinyanga. The second aim was to determine factors that motive men to visit the locally available $\mathrm{RH}$ services.

\section{Materials and Methods}

\section{Study area and design}

The study was carried out in Shinyanga District in north-western Tanzania. The area has a population of approximately 496,800 people and majority of them are of Sukuma ethnicity. The district has a total of 34 dispensaries and 4 health centres. This cross-sectional study used a mixed methods of data collection. A house-to-house survey was carried out in the community and indepth interviews were conducted with men who visited $\mathrm{RH}$ clinics with their partners. The community survey was carried out at Tinde, Samuye and Nindo villages. Randomly selected households were involved in the house-to-house survey. Men married to and living with women of reproductive age were included as participants. The in-depth interviews were conducted in 3 purposively selected RH clinics in Shinyanga rural (Tinde, Samuye and Nindo Health centres). The house-to-house survey involved 204 married men justified by the previously reported proportion of RH male attendance in Tanzania (Msuya et al., 2008). In-depth interviews were also conducted with married men attending $\mathrm{RH}$ services with their partners. 


\section{Data collection}

Data collection was done between August and October 2015. A pretested semi-structured questionnaire was used to interview men on their socio-demographic characteristics, awareness and attendance of RH services and invitation by partner to the RH amenities. In-depth interviews were conducted to the male partners attending $\mathrm{RH}$ services on private location within the health facilities. The purpose of this interview was to understand the factors that motivated the married men to attend $\mathrm{RH}$ health services. The interviews were recorded and field notes were taken in short hand by the interviewer; transcription of the interviews were done on daily basis (Halcomb \& Davidson, 2006).

\section{Data analysis}

The data from the structured questionnaire was entered and analysed using SPSS version 20 software. Frequency distributions on demographic variables were computed. Association RH male attendance with some socio-demographics were done using chi-square or fisher's exact tests. The transcribed qualitative data from the interviews was reviewed to identify different emerging themes associated with factors that motivated men's attendance to RH clinics. After all of the interviews were reviewed similar themes associated with factors that men's attendance at RH clinics were identified. The themes that emerged were then examined and classified as per source of motivation or reason for attendance.

\section{Ethical considerations}

The study was approved by the joint ethical and research committee of the Catholic University of Health and Allied Sciences and the Bugando Medical Centre. Permission to conduct the study was also obtained from Shinyanga District Council Executive Director, Wards Executive Officers and village leaders. All participants approached consented in writing to participate in the study.

\section{Results}

\section{Socio-demographics of the study participants}

A total of 204 married men (mean age $=32.27 \pm 9.68$ years) participated in the house-to-house community survey. The majority were between 25 and 34 years of age. Most participants were from rural areas (68.6\% (140/204). Slightly over half, 58.8\% (120/204) had primary education whereas $31.1 \%(65 / 204)$ had no formal education. Most of the respondents were subsistence farmers and about half of men had 0-2 children family size (Table 1 ).

Table 1: Demographic characteristics of the respondents

\begin{tabular}{llll}
\hline Variables & Variable & Frequency (N=204) & Percentage (\%) \\
\hline Age (years) & $15-24$ & 51 & 25.0 \\
& $25-34$ & 80 & 39.2 \\
Residence & $35-44$ & 43 & 21.1 \\
& Above 45 & 30 & 14.7 \\
Education level & Urban & 64 & 31.4 \\
& Rural & 140 & 68.6 \\
& None & 65 & 31.9 \\
Religion & primary school & 120 & 58.8 \\
& Secondary school & 13 & 6.4 \\
& College and above & 6 & 2.9 \\
& Christians & 97 & 47.5 \\
Occupation & Muslims & 24 & 11.8 \\
& No religion & 81 & 37.7 \\
& Others & 2 & 1.0 \\
& Peasant & 167 & 81.9
\end{tabular}




\begin{tabular}{llll} 
& Business & 22 & 10.8 \\
& Employed & 11 & 5.4 \\
Number of children & None & 4 & 2.0 \\
& $0-2$ & 102 & 50.0 \\
& $3-5$ & 71 & 34.8 \\
& $>5$ & 31 & 15.2 \\
\hline
\end{tabular}

\section{Awareness of married men on reproductive health services}

Almost all of the interviewed men $(95.6 \% ; 195 / 204)$ reported to have heard about RH services as a general term but they never knew the composition of RH service package. The majority of men have heard of family planning services (62.7\% (128/204) and voluntary testing and counselling services for HIV (55.4\% (113/204). In contrast, very few of them had ever heard of reproductive cancer, adolescent reproductive health and sexually transmitted infection, other than HIV (Table 2).

Table 2: Awareness of men on various the reproductive health services

\begin{tabular}{llll}
\hline Service & Response & $\begin{array}{l}\text { Frequency } \\
(\mathbf{N})=\mathbf{2 0 4}\end{array}$ & Percentage (\%) \\
\hline FP & Yes & 128 & 62.7 \\
VCT & No & 76 & 37.3 \\
& Yes & 113 & 55.4 \\
PMTCT & No & 91 & 44.6 \\
& Yes & 25 & 12.3 \\
STIs/STDs & No & 179 & 87.7 \\
& Yes & 63 & 30.9 \\
ANC & No & 141 & 69.1 \\
& Yes & 56 & 27.5 \\
RC & No & 148 & 72.5 \\
& Yes & 10 & 4.9 \\
AS & No & 194 & 95.1 \\
& Yes & 10 & 4.9 \\
\hline
\end{tabular}

FP: Family planning; VCT: Voluntary testing and counselling; PMTCT: Prevention of mother to child transmission of HIV; STIS/STDs: Sexual transmitted infections/sexual transmitted diseases; RC: Reproductive cancers; AS: Adolescent services

Married men attendance to reproductive health services and the associated socio-demographic factors

Almost all respondents reported being aware of a place where $\mathrm{RH}$ services could be obtained and had ever participated in at least one RH service (92.6\% (189/204). Of the interviewees, $5.4 \%(11 / 204)$ had never attended any RH service, 22.5\% (46/204) attended only once, 21.6\% (44/204) attended twice and about half (50.6\% (103/204) attended more than three times. The majority of men reported visiting HIV voluntary counselling and testing (VCT) along with their partners $(75.5 \%$ (154/204) and 63.2\% (129/204) attended antenatal care (ANC) services. Family planning (18.1\% (37/204), sexually transmitted infections (STIs) (9.8\% (20/204) and prevention of HIV transmission from mother to child (PMTCT) $(2 \%$ (4/204) clinics had the lowest reported attendance rate. More than three quarters $(78.4 \%$ (160/204) of the respondents reported to have ever been invited by their spouses to attend at least one of the RH services at the health facility. Antenatal care (ANC) (62.3\% (127/204) and VCT services (44.6\% (91/204) emerged as the top cause of solicitations. Fewer invitations were offered to family planning, PMTCT and STIs services. 
This study also explored the association between the socio-demographic factors and male attendance at RH clinics. Age 25-34 years $\left(\chi^{2}=9.347\right.$; $d f=3$; $p$-value $\left.<0.001\right), 0-2$ number of children $\left(\chi^{2}=6.201 ; \mathrm{df}=2 ; p\right.$-value $\left.<0.05\right)$ and verbal invitation from the female partner $\left(\chi^{2}=29.901 ; \mathrm{df}=1 ; p\right.$ value $<0.001$ ) were found to be associated with increased likelihood of male partner attendance. Level of education, religion, place of residence (rural or urban) and occupation were not associated with increased attendance (Table 3).

Table 3: Association between men attendance to any reproductive health service and some sociodemographic variables

\begin{tabular}{|c|c|c|c|c|c|}
\hline \multirow[t]{2}{*}{ Variable } & & \multicolumn{2}{|l|}{ Attendance } & \multirow{2}{*}{$\begin{array}{l}\text { Chi- } \\
\text { square }\end{array}$} & \multirow[t]{2}{*}{$\mathrm{p}$-value } \\
\hline & & Yes & No & & \\
\hline \multirow{3}{*}{ Age (years) } & $15-24$ & $26(12.7 \%)$ & $25(12.3 \%)$ & 15.47 & 0.001 \\
\hline & $25-34$ & $64(31.4 \%)$ & $16(7.8 \%)$ & & \\
\hline & $35-44$ & $31(15.2 \%)$ & $12(5 \cdot 9 \%)$ & & \\
\hline \multirow{3}{*}{ Residence } & $>40$ & $25(12.3 \%)$ & $5(2.5 \%)$ & & \\
\hline & Urban & $44(21.6 \%)$ & $24(9.8 \%)$ & 0.36 & 0.546 \\
\hline & Rural & $102(50 \%)$ & $38(18.6 \%)$ & & \\
\hline \multirow[t]{4}{*}{ Education level } & None & $50(24 \%)$ & $15(7.4 \%)$ & 6.32 & 0.113 \\
\hline & Primary & $79(38.7 \%)$ & $41(20.1 \%)$ & & \\
\hline & Secondary & $11(5.4 \%)$ & $2(1.0 \%)$ & & \\
\hline & College & $6(2.9 \%)$ & $0(0.0 \%)$ & & \\
\hline \multirow[t]{4}{*}{ Occupation } & Peasant & $117(57.4 \%)$ & $50(24.5 \%)$ & 3.48 & 0.315 \\
\hline & Business & $17(8.3 \%)$ & $5(2.5 \%)$ & & \\
\hline & Employed & $10(4.9 \%)$ & $1(0.5 \%)$ & & \\
\hline & None & $2(1.0 \%)$ & $2(1.0 \%)$ & & \\
\hline \multirow{3}{*}{$\begin{array}{l}\text { Number } \\
\text { children }\end{array}$} & $0-2$ & $65(31.9 \%)$ & $37(18.1 \%)$ & 6.20 & 0.045 \\
\hline & $3-5$ & $56(27.5 \%)$ & $15(7.4 \%)$ & & \\
\hline & $>5$ & $25(12.3 \%)$ & $6(2.9 \%)$ & & \\
\hline \multirow{2}{*}{$\begin{array}{l}\text { Partner } \\
\text { invitation }\end{array}$} & Yes & $129(80.6 \%)$ & $31(19.4 \%)$ & 29.90 & 0.000 \\
\hline & No & $17(38.6 \%)$ & $27(61.4 \%)$ & & \\
\hline
\end{tabular}

\section{Barriers to RH male partner attendance}

Reported factors that were linked with poor male partner involvement in the RH services included fear of the side effects associated with uptake of RH services, such as side effects of family planning methods, fear of HIV/AIDS test results, perception that RH services are for women only. Other factors included view that RH services were not consistent with the individual's religious faith, lack of information on RH services, piecemeal sensitization programs, lack of comprehensive provision of RH services in health facilities and traditional beliefs (Table 4).

\section{Factors motivating male partner attendance to reproductive health services}

Factors associated with male attendance at $\mathrm{RH}$ services were a sense of responsibility to accompany the partner to $\mathrm{RH}$ services; attending the $\mathrm{RH}$ services in order to fulfil the requirement of service providers; coincidental visits (couples attended the health facility/clinic for different individual reasons). Four out of twenty interviewed men reported to have escorted their partners to RH service visits, especially antenatal care visits, because they knew it would be beneficial. They did it as they knew their wives needed them to show extra affection and more care during pregnancy and post-delivery. Most of these men indicated that antenatal care, and voluntary counselling and testing were the most important services to attend with their partners. One man 
said "The first reason is to show my love to my wife especially when she is pregnant. During this time women need [more] love and care than ever before". Some of the men reported that they accompanied their partners to ANC clinics to learn directly from the RH clinic service providers about the pregnancy and the health of the mother. One participant said, "I wanted to know the condition of the baby and if my wife had any problem" and another one commented that "I attended to know my health status as we talked with my wife on the need to test for HIV. I also wanted to get more explanation concerning the pregnancy, and in case of any problem we will know how it can be solved". Some reported to have attended the RH services because they wanted to understand their HIV status and that of their wives. One man stated "I attended VCT with my wife, the reason being need to know our HIV status because there are many risks. Knowing our status was important to both my wife and myself". Some also had a good understanding on the dangers of sexually transmitted diseases and their consequences to their partners. One man stated "I feared that, if I had the virus without my knowledge, then realize after being sick, my health condition could worsen. So I have to regularly come to the VCT for testing and share results with my wife".

Table 4: Reported perceived barriers on male participation in the Reproductive health services

\begin{tabular}{lll}
\hline Factors hindering male participation & Frequency & Percentage (\%) \\
\hline Fear of side effects & 50 & 24.5 \\
RH services are for women only not for men & 108 & 52.9 \\
RH services are against my faith & 108 & 52.9 \\
Lack of enough information on RH & 147 & 72.1 \\
Inadequate information from Health Care Workers & 3 & 1.5 \\
Lack of quality services & 32 & 15.7 \\
RH services are for adolescents only & 7 & 3.4 \\
Fear of HIV test results & 18 & 8.8 \\
Traditions & 19 & 9.3 \\
\hline
\end{tabular}

RH: Reproductive Health

Thirteen of twenty interviewed men stated that they attended RH services because they were summoned by healthcare providers or because their wives were denied services until when they made a visit as a couple. One man stated that "When my wife was pregnant, she went alone to the hospital, the doctor told her to come back home and take me with her to the clinic. So I had no option other than going with her to the clinic". Another commented "There are conditions that we were given. You can tell your wife to go alone to the clinic, but she will not be treated unless you are also there".

Three out of twenty interviewees reported to attend RH services simply because they happened to be at the health facilities. One man commented "I attended the service as I had to escort my wife who was sick and therefore decided to check my health status as well". Another one also stated "We brought our sick child with my wife and so I decided to test for HIV and to know my health status".

\section{Discussion}

Male involvement in RH services in Tanzania is extremely important as male partners can positively influence family planning, birth preparedness and other services as they hold the socio-cultural and economic power in the family (Angel-Urdinola \& Wodon, 2010; Ganle et al., 2015). The current study found more than $70 \%$ of the male partners had ever attended RH services at least twice in Shinyanga. This rate of attendance was higher than the previously been reported in the same region (Msuya et al., 2008; Becker et al., 2010; Byamugisha et al., 2011). This difference could be due to the fact that the present study was a retrospective one that inquired about any history of attendance at community $\mathrm{RH}$ clinics with their partners, whereas the previous studies investigated 
attendance at hospital-based clinics and used prospective approaches. Most of the male participants in the present study attended ANC, VCT care and family planning services whereas very few had ever attended reproductive cancer, PMTCT and STI/STD clinics. This is consistent with other studies in developing countries, which reported low participation rates among men in $\mathrm{RH}$ services (Tobin et al., 2014; Tilahun \&Mohamed, 2015).

To reduce maternal and child mortalities, Tanzanian Ministry of Health has emphasized the importance of family planning and child spacing (MoHSW, 2014). This study, however, found very low male involvement in family planning services which is consistent with findings from the recent demographic and health surveys (TDHS-MIS, 2016). Male attendance to RH services was associated with age and the highest attendance was found among the 25-34 years age group. This was possibly due to the fact that men of this particular age group are young and could be easily reached by health information and education using different communication media. Similar findings and reasons have been reported by other studies in Africa (Nkuoh et al., 2010; Tilahun \& Mohamed, 2015; Zenebe et al., 2016). Consistent with previous studies as having less than 2 children in the family was associated with male attendance to RH clinics and could be reflection of couple engagement in family planning (Shahjahan et al., 2013; Butto \& Mburu, 2015). Verbal invitations by female partners to attend $\mathrm{RH}$ care was strongly associated with male attendance. This is in consistent with other studies in East Africa (Nantamu, 2011; Theuring et al., 2016). In contrast to previous studies, no association was found between male involvement in $\mathrm{RH}$ services and religion, education or occupation (Butto \& Mburu, 2015; Shahjahan et al., 2013). This could be due to that fact that population of men who participated in this study were relatively homogeneous in terms of their socio-demographic characteristics (i.e., subsistence farmers with primary level education).

Despite of the high invitation rate from female partners, some men perceived that $\mathrm{RH}$ services were for women and lacked appropriate information about their role in $\mathrm{RH}$. This suggests that there may have been ineffective communication between husbands and wives on RH matters. Similar findings have been reported in other studies in African settings (Akarro et al., 2011; Kululanga et al., 2012; Kabagenyi et al., 2014). Other factors that may have influenced male attendance to $\mathrm{RH}$ services included lack of consistence with their religious beliefs (i.e., some family planning methods), unfriendly health workers and lack of quality and specialized male- friendly services. All of these barriers have been as well highlighted by other studies done in Sub-Sahara Africa (Sarker et al., 2007; Byamugisha et al., 2010). In order to improve male participation in RH, the local health authorities should implement community based programmes that focus on male partner stigma reduction of fear associated with HIV disclosure, improve awareness and improve the quality of healthcare services (Osman et al., 2014). As male involvement in RH services improves, policies and resources should be directed to more engagement of male partners and creation of the male friendly service delivery in health facilities.

Motivation is known to improve performance of individuals in their assigned duties and foster spirit of sustainability and creativity (Bonenberger et al., 2014). Internal motivation is better than the external motivation, as it is more likely to sustain behaviour and is not easily affected by external factors. In the current study it appeared that most of the men's attendance to RH clinics were motivated by extrinsic factors. To reduce maternal and child mortalities and achieve birth control, the engagement of RH motivate male partners is pivotal. Their involvement in $\mathrm{RH}$ while intrinsically motivated could greatly and sustainably improve the key maternal and child health indicators (Aluisio et al., 2011; Yargawa \& Leonardi-Bee, 2015). Identification of high impact motivators that could result in improved participation of male partners in $\mathrm{RH}$ services in Shinyanga need to be explored.

This study had some limitation as it had some homogeneity among the participants; most were from rural areas and were subsistent farmers. So this data is limited in its generalizability, particularly to male partners who live in urban communities in Tanzania. In conclusion, the high rate male attendance at RH clinics in Shinyanga District was mainly related to VCT and ANC services. Invitation from the female partner was a strong predictor to the service attendance meanwhile 
most of men who attended RH seem extrinsically motivated. This study recommend increased sensitization and awareness campaign on the Tanzania RH service package and educate women of reproductive age on the effective $\mathrm{RH}$ communication with male partners. In addition, male friendly services need to be incorporated into RH clinics. Future behavioural research on how best male partners can be extrinsically and intrinsically motivated to participate in $\mathrm{RH}$ clinics is essential in order to ensure sustained male involvement to reproductive health.

\section{Competing interests}

The authors affirm that they have no competing interests.

\section{Authors' contributions}

EN, ECN, NB, EK, and DD participated in the conception and design of the study and drafting of the manuscript. EC participated in the conception and design of the study, statistical analysis and interpretation of the data. AK, AC, OJ and JS participated in conception, design, and implementation of the study, statistical analysis and AK drafted the manuscript.

\section{Acknowledgements}

Authors are grateful to all men who participated in this study for their time and patience. We also acknowledge the support from the Shinyanga District Council, the District Medical Office and the Engender Health Office-Shinyanga. We also appreciate the contributions of the health facility incharges at Tinde, Samuye and Nindo Health centres during data collection. This study was funded by the Bristol-Myers Squibb Foundations through TOUCH Foundation Community-based Research (CBR) project of the Catholic University of Health and Allied Sciences-Bugando.

\section{References}

Afnan-Holmes, H., Magoma, M., John, T., Levira, F., Msemo, G., Armstrong, C. E., Martínez-Álvarez, M., Kerber, K., Kihinga, C. \& Makuwani, A. (2015) Tanzania's countdown to 2015: an analysis of two decades of progress and gaps for reproductive, maternal, newborn, and child health, to inform priorities for post-2015. Lancet Global Health 3: e396-e409.

Akarro, R.R., Deonisia, M. \& Sichona, F. (2011) An evaluation of male involvement on the programme for PMTCT of HIV/AIDS: a case study of Ilala Municipality in Dar es Salaam, Tanzania. Arts Social Science Journal 20: 1.

Allen, S., Tice, J., Van De Perre, P., Serufilira, A., Hudes, E., Nsengumuremyi, F., Bogaerts, J., Lindan, C. \& Hulley, S. (1992) Effect of serotesting with counselling on condom use and seroconversion among HIV discordant couples in Africa. BMJ 304: 1605-1609.

Aluisio, A., Richardson, B. A., Bosire, R., John-Stewart, G., Mbori-Ngacha, D. \& Farquhar, C. (2011) Male antenatal attendance and HIV testing are associated with decreased infant HIV infection and increased HIV free survival. Journal of Acquired Immune Deficiency Syndromes 56: 76.

Anasel, M. G. \& Mlinga, U.J. ( 2014) Determinants of contraceptive use among married women in Tanzania: Policy implication. Etude de la Population Africaine 28: 976.

Angel-Urdinola, D. \& Wodon, Q. (2010) Income generation and intra-household decision making: A gender analysis for Nigeria. Gender Disparities in Africa's Labor Market 381.

Bajunirwe, F. \& Muzoora, M. (2005) Barriers to the implementation of programs for the prevention of mother-to-child transmission of HIV: a cross-sectional survey in rural and urban Uganda. AIDS Research and Therapy 2(1): 10. 
Becker, S., Mlay, R., Schwandt, H. M. \& Lyamuya, E. (2010) Comparing couples' and individual voluntary counseling and testing for HIV at antenatal clinics in Tanzania: a randomized trial. AIDS and Behavior 14: 558-566.

Bonenberger, M., Aikins, M., Akweongo, P. \& Wyss, K. (2014) The effects of health worker motivation and job satisfaction on turnover intention in Ghana: a cross-sectional study. Human Resources for Health 12: 10.1186.

Butto, D. \& Mburu, S. (2015) Factors Associated with Male Involvement in Family Planning in West Pokot County, Kenya. Universal Journal of Public Health 3: 160-168.

Byamugisha, R., Åstrøm, A.N., Ndeezi, G., Karamagi, C.A., Tylleskär, T. \& Tumwine, J.K. (2011) Male partner antenatal attendance and HIV testing in eastern Uganda: a randomized facilitybased intervention trial. Journal of the International AIDS Society 14: 43.

Byamugisha, R., Tumwine, J. K., Semiyaga, N. \& Tylleskär, T. (2010) Research determinants of male involvement in the prevention of mother-to-child transmission of HIV programme in Eastern Uganda: a cross-sectional survey. Reproductive Health 7: 12.

Chuwa, M. (2012) Male involvement in family planning practice. African Journal of Midwifery and Women's Health 6: 132-138.

Cleland, J. G., Ndugwa, R. P. \& Zulu, E. M. (2011) Family planning in sub-Saharan Africa: progress or stagnation? Bulletin of the World Health Organization 89: 137-143.

Ditekemena, J., Koole, O., Engmann, C., Matendo, R., Tshefu, A., Ryder, R. \& Colebunders, R. (2012) Determinants of male involvement in maternal and child health services in sub-Saharan Africa: a review. Reproductive Health 9: 32.

Ditekemena, J., Matendo, R., Koole, O., Colebunders, R., Kashamuka, M., Tshefu, A., Kilese, N., Nanlele, D. \& Ryder, R. (2011) Male partner voluntary counselling and testing associated with the antenatal services in Kinshasa, Democratic Republic of Congo: a randomized controlled trial. International Journal of STD \& AIDS 22: 165-170.

Ganle, J. K., Obeng, B., Segbefia, A. Y., Mwinyuri, V., Yeboah, J. Y. \& Baatiema, L. (2015) How intrafamilial decision-making affects women's access to, and use of maternal healthcare services in Ghana: a qualitative study. BMC Pregnancy \& Childbirth 15: 1.

Haile, F. \& Brhan, Y. (2014) Male partner involvements in PMTCT: a cross sectional study, Mekelle, Northern Ethiopia. BMC Pregnancy and Childbirth 14: 1.

Halcomb, E. J. \& Davidson, P. M. (2006) Is verbatim transcription of interview data always necessary? Applied Nursing Research 19: 38-42.

Kabagenyi, A., Jennings, L., Reid, A., Nalwadda, G., Ntozi, J. \& Atuyambe, L. (2014) Barriers to male involvement in contraceptive uptake and reproductive health services: a qualitative study of men and women's perceptions in two rural districts in Uganda. Reproductive Health 11: 21.

Kak, L., Chitsike, I., Luo, C. \& Rollins, N. (2011) Prevention of mother-to-child transmission of HIV/AIDS programmes. Opportunities for Africa's newborns: Practical data, policy and programmatic support for newborn care in Africa http://www.who.int/pmnch/media/publications/oanfullreport.pdf.

Kululanga, L., Sundby, J., Chirwa, E., Malata, A. \& Maluwa, A. (2012) Barriers to husbandsâ involvement in maternal health care in a rural setting in Malawi: a qualitative study. Journal of Research in Nursing and Midwifery 1: 1-10.

Medley, A., Garcia-Moreno, C., Mcgill, S. \& Maman, S. (2004) Rates, barriers and outcomes of HIV serostatus disclosure among women in developing countries: implications for prevention of mother-to-child transmission programmes. Bulletin of the World Health Organization 82: 299-307.

Michael, E. (2012) Use of contraceptives methods among women in stable marital relations attending health facilities in Kahama district, Shinyanga region, Tanzania. Doctoral dissertation of the Muhimbili University of Health and Allied Sciences. www.muhas.ac.tz 
Msuya, S., Mbizvo, E., Hussain, A., Uriyo, J., Sam, N. \& Stray-Pedersen, B. (2008) Low male partner participation in antenatal HIV counselling and testing in northern Tanzania: implications for preventive programs. AIDS Care 20: 700-709.

Nantamu, D. (2011) Factors Associated with Male Involvement in Maternal Health Care services in Jinja District, Uganda. MPH Dissertation, Makerere University School of Public Health, Kampala, Uganda.

Nkuoh, G. N., Meyer, D. J., Tih, P. M. \& Nkfusai, J. (2010) Barriers to Men's Participation in Antenatal and Prevention of Mother-to-Child HIV Transmission Care in Cameroon, Africa. Journal of Midwifery \& Women's Health 55: 363-369.

WHO (2002) Programming for male involvement in reproductive health: report of the meeting of WHO regional advisers in reproductive health. World Health Organization, Geneva, Switzerland.

Osman, R. J., Unkels, R., Aliyu, U., Musa, H., Adpa, A. \& Mathew, O. (2014) Barriers to male involvement in uptake of Prevention-of-Mother-to-Child-Transmission (PMTCT) of HIV in Sub-Saharan Africa. IOSR Journal of Nursing and Health Science 3: 01-07.

Peltzer, K., Jones, D., Weiss, S. M. \& Shikwane, E. (2011) Promoting male involvement to improve PMTCT uptake and reduce antenatal HIV infection: a cluster randomized controlled trial protocol. BMC Public Health 11: 778.

Reece, M., Hollub, A., Nangami, M. \& Lane, K. (2010) Assessing male spousal engagement with prevention of mother-to-child transmission (PMTCT) programs in western Kenya. AIDS Care 22: 743-750.

Ryan, R. M. \& Deci, E. L. (2000a) Intrinsic and extrinsic motivations: Classic definitions and new directions. Contemporary Educational Psychology 25: 54-67.

Ryan, R. M. \& Deci, E. L. (2000b) Self-determination theory and the facilitation of intrinsic motivation, social development, and well-being. American Psychologist 55: 68.

Sarker, M., Sanou, A., Snow, R., Ganame, J. \& Gondos, A. (2007) Determinants of HIV counselling and testing participation in a prevention of mother-to-child transmission programme in rural Burkina Faso. Tropical Medicine \& International Health 12: 1475-1483.

Shahjahan, M., Mumu, S. J., Afroz, A., Chowdhury, H. A., Kabir, R. \& Ahmed, K. (2013) Determinants of male participation in reproductive healthcare services: a cross-sectional study. Reproductive Health 10: 27.

Singh, S., Darroch, J. E., Vlassoff, M. \& Nadeau, J. (2003) Adding it up. The benefits of investing in sexual and reproductive health care. https://www.unfpa.org/sites/default/files/pubpdf/addingitup.pdf

MoHSW (2014) National Road Map Strategic Plan to Accerelate Reduction of Maternal, Newborn and Child Deaths in Tanzania 2008-2015. Ministry of Health and Social Welfare, Dar es Salaam, Tanzania.

Sternberg, P. \& Hubley, J. (2004) Evaluating men's involvement as a strategy in sexual and reproductive health promotion. Health Promotion International 19: 389-396.

TDH-MIS (2016) Tanzania Demographic and Health Survey and Malaria Indicator Survey. Ministry of Helath, Community Development, Gender, Elderly and Children (Tanzania Mainland), Ministry of Health (Zanzibar), National Bureau of Statistics, Office of the Chief Government Statistician, and ICF. Dar es Salaam, Tanzania and Rockville, Maryland, USA.

Theuring, S., Jefferys, L. F., Nchimbi, P., Mbezi, P. \& Sewangi, J. (2016) Increasing Partner Attendance in Antenatal Care and HIV Testing Services: Comparable Outcomes Using Written versus Verbal Invitations in an Urban Facility-Based Controlled Intervention Trial in Mbeya, Tanzania. PloS One 11: e0152734.

Tilahun, M. \& Mohamed, S. (2015) Male Partners' Involvement in the Prevention of Mother-to-Child Transmission of HIV and Associated Factors in Arba Minch Town and Arba Minch Zuria Woreda, Southern Ethiopia. BioMed Research international, 2015. Article ID 763876. http://dx.doi.org/10.1155/2015/763876 
Tobin, E. A., Ofili, A. N., Enebeli, N. \& Enueze, O. (2014) Assessment of birth preparedness and complication readiness among pregnant women attending Primary Health Care Centres in Edo State, Nigeria. Annals of Nigerian Medicine 8: 76.

UNICEF. (2005) The State of the World's Children 2006: Excluded and Invisible. UNICEF.

Yargawa, J. \& Leonardi-Bee, J. (2015) Male involvement and maternal health outcomes: systematic review and meta-analysis. Journal of Epidemiology and Community Health 0:1-9.

Zenebe, A., Gebeyehu, A., Derseh, L. \& Ahmed, K. Y. (2016) Male partner's involvement in HIV counselling and testing and associated factors among partners of pregnant women in Gondar Town, Northwest Ethiopia. Journal of Pregnancy, 2016. http://dx.doi.org/10.1155/2016/3073908 